\title{
Substituição da silagem de milho por silagem de girassol na dieta de novilhos em confinamento: comportamento ingestivo
}

\section{Leandro da Silva Freitas ${ }^{1}$, José Henrique Souza da Silva ${ }^{2}$, Luciane Rumpel Segabinazzi ${ }^{1}$, Viviane Santos da Silva ${ }^{3}$, Dari Celestino Alves Filho², Ivan Luiz Brondani²}

\author{
1 Programa de Pós-Graduação em Zootecnia - UFSM, Santa Maria-RS, CEP: 97105-900. \\ 2 Departamento de Zootecnia da UFSM. \\ ${ }^{3}$ Curso de graduação em Zootecnia da UFSM.
}

RESUMO - Estudaram-se os efeitos da substituição na dieta da silagem de milho por silagem de girassol (0, 33 e $66 \%$ MS) no comportamento ingestivo de novilhos em confinamento. Utilizaram-se nove novilhos castrados com peso vivo e idade média inicial de $288 \mathrm{~kg}$ e 20 meses, respectivamente, pertencentes aos grupos genéticos Nelore, 21/32Charolês (C) 11/32Nelore (N) e $21 / 32 \mathrm{~N} \mathrm{11/32C.} \mathrm{O} \mathrm{delineamento} \mathrm{experimental} \mathrm{utilizado} \mathrm{foi} \mathrm{o} \mathrm{de} \mathrm{blocos} \mathrm{ao} \mathrm{acaso,} \mathrm{com} \mathrm{três} \mathrm{repetições} \mathrm{por} \mathrm{tratamento.}$ As dietas testadas foram: $100 \%$ de silagem de milho e $0 \%$ de silagem de girassol; $70,94 \%$ de silagem de milho e $29,06 \%$ de silagem de girassol; $38,27 \%$ de silagem de milho e $61,73 \%$ de silagem de girassol, todas com relação volumoso:concentrado 60:40. O tempo destinado ao ócio deitado foi maior para os novilhos que consumiram apenas silagem de milho como volumoso em relação aos que consumiram silagem de girassol. O tempo despendido em ócio em pé foi semelhante entre as dietas com 33 (1,84 hora) e $66 \%$ de silagem de girassol (1,96 hora) e menor para aquela sem silagem de girassol (1,62 hora). O tempo em ruminação dos animais aumentou com a inclusão da silagem de girassol na dieta e correspondeu a 8,$61 ; 8,76$ e 9,45 horas, respectivamente, para $0 ; 33$ e $66 \%$ de silagem de girassol. Animais alimentados somente com silagem de milho apresentam maior eficiência de ruminação da matéria seca e da fibra em detergente neutro. O tempo despendido por refeição diminui com o aumento da participação da silagem de girassol.

Palavras-chave: ócio, ruminação, tempo de alimentação, teor de gordura, volumoso

\section{Corn silage substituted by sunflower silage in the diet of fedlot steers: ingestive behavior}

\begin{abstract}
The objective of this experiment was to evaluate the effect of replacing corn silage with sunflower silage $(0,33$ e $66 \% \mathrm{DM})$ on the ingestive behavior of fedlot steers. Nine castrated steers were used, with average $288 \mathrm{~kg}$ initial live

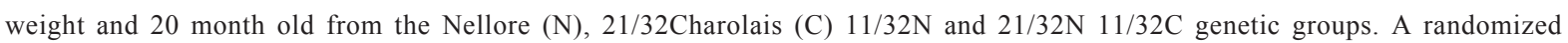
complete block experimental design was used, with three replications per treatment. The tested diets were: $100 \%$ corn silage and $0 \%$ sunflower silage; $70.94 \%$ corn silage and $29.06 \%$ sunflower silage and $38.27 \%$ corn silage and $61.73 \%$ sunflower silage, all with a 60:40 roughage:concentrate ratio. Time spent lying idle was greater for steers that consumed only corn silage as roughage compared to those that consumed sunflower silage. Time spent standing idle was similar between 33 (1.84 h) and $66 \%$ sunflower silage $(1.96 \mathrm{~h})$ and lower for $0 \%$ sunflower silage $(1.62 \mathrm{~h})$. The animals rumination time increased with the inclusion of sunflower on diet, with values of $8.61 ; 8.76$ and $9.45 \mathrm{~h}$, respectively for $0 ; 33$ and $66 \%$ sunflower silage. Animals fed only with corn silage show better dry matter and neutral detergent fiber rumination efficiencies. The time spent feeding decrease with higher participation of sunflower silage.
\end{abstract}

Key Words: fat concentration, feeding time, idle time, roughage, rumination

\section{Introdução}

O grau de entendimento dos fatores que influenciam no comportamento dos animais nas diferentes fases da vida e dos sistemas de criação é de grande importância para planejar, executar e interpretar resultados de pesquisa (Hafez \& Lindsay, 1965; Albright, 1993).
O comportamento alimentar tem sido estudado considerando as características químico-físicas do alimento, a motilidade dos pré-estômagos, o estado de vigília e o ambiente climático (Dulphy etal., 1980; Forbes, 1995).

O desempenho animal é influenciado pela ingestão de matéria seca e seu consumo pode ser afetado pelo teor de gordura da dieta. Normalmente o teor de gordura de 3 a $5 \%$ 
é considerado limite benéfico na alimentação de bovinos (Shauff et al., 1992), no entanto, teores de gordura acima de $7 \%$ na dieta de ruminantes inibem a fermentação ruminal (Kozloski, 2002).

Redução de 1,29 kg no consumo de matéria seca em vacas da raça Holandesa que receberam infusão abomasal de uma mistura de $50 \%$ de óleo de girassol e 50\% de óleo de canola em relação àquelas que receberam infusão de água (controle) foi relatada por Benson et al. (2001). No entanto, esses autores não constataram diferenças significativas entre os tempos diários despendidos com ingestão, ruminação e descanso.

Estudando o comportamento ingestivo de vacas Jersey alimentadas com diferentes fontes de gordura na dieta, Salla et al. (2003) verificaram que as fontes de gordura não influenciaram $(\mathrm{P}>0,05)$ as atividades comportamentais e o consumo de matéria seca e fibra em detergente neutro e que o nível de EE consumido foi de 3,67; 5,92; 6,70 e 6,29 \% para as dietas controle, sebo, gordura protegida e grão de soja, respectivamente. Ao estudar o comportamento ingestivo de diferentes categorias alimentadas com $40 \%$ de silagem de milho e 3,8\% de EE, Ferreira (2006) observou menor número de mastigações/bolo e por kg de MS para as vacas, enquanto os novilhos apresentaram menor taxa de ingestão e não houve diferença significativa nas atividades de ruminação, ócio, ingestão de água e consumo de alimento.

No entanto, na literatura são raros os estudos com avaliação do efeito da gordura da dieta no comportamento alimentarde ruminantes. O objetivo neste trabalho foi avaliar a influência da substituição da silagem de milho por silagem de girassol sobre as atividades alimentares de novilhos em confinamento.

\section{Material e Métodos}

O experimento foi conduzido no período de junho a outubro de 2006 no Laboratorio de Bovinocultura de Corte do Departamento de Zootecnia da Universidade Federal de Santa Maria (UFSM), situado na Depressão Central do Rio Grande do Sul. Foram utilizados nove novilhos castrados, do mesmo rebanho, com peso vivo e idade média inicial de $288 \mathrm{~kg}$ e 20 meses, pertencentes aos grupos genéticos Nelore (N), 21/32Charolês (C) 11/32N e 21/32N 11/32C, utilizados na formação dos blocos.

Foi estudado o comportamento ingestivo de novilhos de corte submetidos a três dietas com diferentes níveis de silagem de girassol (0,33 e 66\% MS) em substituição a silagem de milho no volumoso, assim identificadas: $100 \%$ de silagem de milho e $0 \%$ de silagem de girassol; $70,94 \%$ de silagem de milho e $29,06 \%$ de silagem de girassol e $38,27 \%$ de silagem de milho e $61,73 \%$ de silagem de girassol (Tabela 1). A relação volumoso:concentrado utilizada foi de aproximadamente 60:40 (base na matéria seca).

As dietas foram calculadas de acordo com o NRC (1996) para serem isoproteicas, objetivando ganho de peso médio diário (GMD) de 1,2 kg/ animal, com consumo estimado de $2,5 \mathrm{~kg}$ de $\mathrm{MS} / 100 \mathrm{~kg}$ de PV. Os ingredientes utilizados para a formulação dos concentrados foram farelo de glúten de milho, farelo de trigo, milho em grão, calcário calcítico, cloreto de sódio e ureia.

Durante o período de confinamento, os novilhos foram alimentados à vontade, duas vezes ao dia $(8 \mathrm{~h} 30 \mathrm{e}$ $14 \mathrm{~h}$ ), com o concentrado misturado manualmente ao volumoso no cocho no momento da alimentação. Diariamente pela manhã, antes da alimentação, as sobras do dia anterior foram retiradas e pesadas para ajuste da oferta de alimento e posterior cálculo do consumo de matéria seca. As sobras de alimentos foram mantidas entre 5 e $8 \%$ do total ofertado.

Amostras representativas dos componentes da dieta alimentar e das sobras foram coletadas no início da adaptação e duas vezes por semana durante o período experimental. As amostras foram pré-secas em estufa de ar forçado a $55^{\circ} \mathrm{C}$, por 72 horas para determinação da matéria parcialmente seca. Posteriormente, foram processadas em moinho tipo Willey com peneira com crivos de $1 \mathrm{~mm}$ e armazenadas para posterior análise laboratorial. Foram determinados os teores de matéria seca (MS) e matéria orgânica (MO), proteína bruta (PB), extrato etéreo (EE) e

Tabela 1 - Composição das dietas experimentais (\% MS)

\begin{tabular}{lccc}
\hline & \multicolumn{3}{c}{$\begin{array}{c}\text { Nível de silagem de } \\
\text { girassol (\%MS) }\end{array}$} \\
\cline { 2 - 4 } & 0 & 33 & 66 \\
\hline Ingrediente (\%) & & 17,0 & 35,0 \\
Silagem de girassol & - & 41,5 & 21,7 \\
Silagem de milho & 59,7 & 19,9 & 12,9 \\
Farelo de glúten de milho & 20,2 & 3,7 & 3,8 \\
Milho grão & 2,9 & 17,1 & 25,8 \\
Farelo de trigo & 16,1 & 0,6 & 0,6 \\
Calcário calcítico & 0,8 & 0,2 & 0,2 \\
Cloreto de sódio & 0,2 & - & - \\
Ureia & 0,1 & & \\
Nutriente & & & \\
Matéria seca (\%) & 53,1 & 52,8 & 52,2 \\
Proteína bruta (\%) & 12,3 & 12,5 & 12,8 \\
Extrato etéreo (\%) & 4,06 & 5,29 & 7,15 \\
Matéria mineral (\%) & 10,26 & 10,35 & 10,40 \\
Fibra em detergente neutro (\%) & 51,7 & 50,9 & 49,7 \\
Fibra em detergente ácido (\%) & 22,8 & 23,1 & 24,1 \\
Lignina (\%) & 3,01 & 3,56 & 3,80 \\
Nutriente digestíveis total (\%) & 64,8 & 65,5 & 66,7 \\
Energia digestível (Mcal/kg) & 2,85 & 2,88 & 2,93 \\
\hline
\end{tabular}

Foram utilizados $50 \mathrm{~g}$ de io nóforo $\left(\right.$ Rumensin ${ }^{\circledR}$ ) para cada $100 \mathrm{~kg}$ de concentrado. 
cinzas (MM), segundo (AOAC, 1995). A determinação da fibra em detergente neutro (FDN) e fibra em detergente ácido (FDA) foi feita em saquinhos de poliéster (Komarek, 1993). Os teores de lignina em detergente ácido (LDA) foram determinados de acordo com Robertson \& Van Soest (1981). Os teores de nitrogênio insolúvel em detergente neutro (NIDN) e nitrogênio insolúvel em detergente ácido (NIDA) foram analisados de acordo com Licitra et al. (1996). O teor de nutrientes digestíveis totais (NDT) foi calculado segundo Weiss et al. (1992).

Antecedendo o período experimental, os animais foram submetidos a um período (17 dias) de adaptação às instalações, ao manejo e as dietas experimentais. Os animais foram alojados em baias individuais de $12 \mathrm{~m}^{2}$, pavimentadas com concreto, cobertas, providas de bebedouros regulados com torneira-boia e comedouros individualizados. A coleta de dados foi feita durante o período de terminação dos animais (104 dias), totalizando oito dias de observações, distribuídos ao longo do experimento (no primeiro, segundo, terceiro e quarto período, em intervalos de 21 dias). A avaliação do comportamento ingestivo consistiu no registro dos tempos diários despendidos com consumo de alimento e ingestão de água, na ruminação e no ócio, deitado ou em pé. As observações das atividades dos animais foram tomadas a cada cinco minutos, durante 48 horas consecutivas, em quatro períodos. Durante todo o período experimental, o período noturno foi mantido com iluminação artificial.

A média do número de mastigações merícicas por bolo ruminal (NMB) e do tempo despendido na mastigação merícica por bolo ruminal (TMB) foram obtidas utilizando-se 24 observações por animal em cada período de avaliação. Para o registro do tempo de mastigações merícicas por bolo ruminal, utilizou-se um cronômetro digital.

Os dados do comportamento ingestivo foram interpretados conforme descrito por Polli et al. (1996) e Burger et al. (2000), em que: ERMS = CMS/TRT; ERFDN = $\mathrm{CFDN} / \mathrm{TRT}$; TMT $=\mathrm{TAL}+\mathrm{TRT}$; $\mathrm{BOL}=\mathrm{TRT} / \mathrm{TMB} ; \mathrm{NMD}=$ $\mathrm{NMB} * \mathrm{BOL} ; \mathrm{TOT}=\mathrm{TOE}+\mathrm{TOD}$ e $\mathrm{TRT}=\mathrm{TER}+\mathrm{TRD} ; \mathrm{em}$ que ERMS ( $\mathrm{g} \mathrm{MS} / \mathrm{h})=$ eficiência de ruminação de MS; CMS ( $\mathrm{g}$ MS/dia) o consumo de MS; ERFDN (g FDN/h) = eficiência de ruminação da fibra em detergente neutro; CFDN ( $\mathrm{g}$ FDN/ $\mathrm{dia})=$ consumo de fibra em detergente neutro; TMT (h/dia) o tempo de mastigação total; TAL $(\mathrm{h} / \mathrm{dia})=$ tempo de alimentação; TRT (h/dia) = tempo de ruminação total; BOL $\left(\mathrm{n}^{\mathrm{O}} / \mathrm{dia}\right)=$ número de bolos mastigados por dia; TMB (seg/ bolo) = tempo de mastigações merícicas por bolo ruminal; $\operatorname{NMD}\left(\mathrm{n}^{\mathrm{o}} / \mathrm{dia}\right)=$ número de mastigações merícicas por dia; TOD $(\mathrm{h} / \mathrm{dia})=$ tempo de ócio deitado; $\mathrm{TOE}(\mathrm{h} / \mathrm{dia})=$ tempo de ócio em pé; TRE $(\mathrm{h} / \mathrm{dia})=$ tempo de ruminação em pé; TRD $(\mathrm{h} /$ dia $)=$ tempo de ruminação deitado; TOT $(\mathrm{h} / \mathrm{dia})=$ tempo de ócio total.

O número de refeições diárias (NRF) foi obtido considerando a permanência do animal no cocho por um tempo mínimo de 10 minutos. A temperatura mínima e máxima no decorrer do dia foi obtida utilizando-se termômetro de máxima e mínima, das $7 \mathrm{~h}$ às $18 \mathrm{~h}$, em cada período de coleta dos dados.

O delineamento experimental utilizado foi de blocos ao acaso, com 3 repetições por tratamento, considerando o animal a unidade experimental. Os resultados obtidos foram submetidos à análise de variância pelo proc GLM e as médias comparadas pelo teste $t$ de Student (PDIFF), com $5 \%$ de significância, pelo teste de correlação de Pearson, com o auxílio do pacote estatístico SAS (2001). O modelo matemático utilizado foi o seguinte: $\gamma_{i j k}=\mu+\tau_{i}+\beta_{j}+\varepsilon_{i j k}$ em que: $\gamma_{i j k}=$ representa as variáveis dependentes; $\mu=$ média geral de todas as observações; $\tau_{i}=$ efeito do $i$-ésimo do tratamento; $\beta_{j}=$ efeito do $j$-ésimo bloco para grupo genético; $\varepsilon_{i j k}=$ erro aleatório residual, $\mathrm{NID}\left(0, \sigma^{2}\right)$. Os dados das variáveis ingerindo água, ócio em pé e ruminando em pé foram analisados após transformação raiz quadrada.

\section{Resultados e Discussão}

O tempo destinado ao consumo de alimento (TAL) foi influenciado pelas dietas (Tabela 2). Os novilhos alimentados com $33 \%$ de silagem de girassol permaneceram mais tempo $(\mathrm{P}<0,05)$ em alimentação $(4,98 \mathrm{~h})$ que aqueles alimentados com $66 \%$ de silagem de girassol $(4,38 \mathrm{~h})$, porém não diferiram daqueles que não receberam silagem de girassol (4,64 horas). No entanto, essa diferença no tempo de alimentação não afetou o consumo de matéria seca (MS) e de fibra em detergente neutro (FDN) (Tabela 3). Estes resultados diferem dos encontrados por Fischer et al. (2001), que forneceram três dietas contendo diferentes fontes de gordura (farelo de arroz + sebo, sais de cálcio e óleo de palma e sebo) a vacas Jersey em lactação e não notaram diferenças no consumo de matéria seca e de FDN nem nas características comportamentais. Da mesma forma, Salla et al. (2003) não constataram diferenças nos tempos destinados a ingestão, ruminação, descanso e consumo de MS e FDN entre as dietas controle, sebo, gordura protegida e grão de soja. O teor de EE consumido foi de 3,$67 ; 5,92 ; 6,70$; e $6,29 \%$ da MS, respectivamente. Ferreira (2006) não observou diferença para nenhuma das variáveis do comportamento ingestivo entre novilhos e vacas de descarte terminadas em confinamento com teor médio de $3,8 \%$ EE na dieta. 
Tabela 2 - Tempos médios despendidos nas atividades comportamentais de novilhos alimentados com diferentes níveis de silagem de girassol na dieta

\begin{tabular}{|c|c|c|c|}
\hline \multirow[b]{2}{*}{ Atividades, horas/dia } & \multicolumn{3}{|c|}{ Nível de silagem de girassol (\%MS) } \\
\hline & 0 & 33 & 66 \\
\hline Alimentação & $4,64 \pm 0,14 \mathrm{ab}$ & $4,98 \pm 0,14 \mathrm{a}$ & $4,38 \pm 0,14 b$ \\
\hline Ócio deitado & $7,91 \pm 0,19 \mathrm{~A}$ & $6,62 \pm 0,19 \mathrm{~B}$ & $6,08 \pm 0,19 \mathrm{C}$ \\
\hline Ócio em pé & $2,69 \pm 0,16 \mathrm{~B}$ & $3,48 \pm 0,16 \mathrm{~A}$ & $3,93 \pm 0,16 \mathrm{~A}$ \\
\hline Ócio total & $10,60 \pm 0,19$ & $10,10 \pm 0,19$ & $10,01 \pm 0,19$ \\
\hline Ruminação deitado & $7,85 \pm 0,14$ & $8,03 \pm 0,14$ & $8,21 \pm 0,14$ \\
\hline
\end{tabular}

Letras maiúsculas distintas, na linha, diferem $(\mathrm{P}<0,01)$ pelo teste $\mathrm{t}$.

Letras minúsculas distintas, na linha, diferem $(\mathrm{P}<0,05)$ pelo teste $\mathrm{t}$.

Tabela 3 - Consumo diário de matéria seca por animal (CMS), por $100 \mathrm{~kg}$ de peso vivo (CMSPV) e consumo de fibra em detergente neutro, eficiência de ruminação da MS e da FDN de novilhos alimentados com diferentes níveis de silagem de girassol na dieta

\begin{tabular}{lrrr}
\hline Item & \multicolumn{3}{c}{ Nível de silagem de girassol (\%MS) } \\
\cline { 2 - 4 } & \multicolumn{1}{c}{0} & \multicolumn{2}{c}{33} \\
\hline Consumo de material seca, kg/dia & $9,07 \pm 0,12$ & $8,69 \pm 0,12$ & $8,19 \pm 0,12$ \\
CMSPV, \% PV & $2,56 \pm 0,12$ & $2,42 \pm 0,12$ & $2,36 \pm 0,12$ \\
Consumo de FDN, kg/dia & $6,13 \pm 0,27$ & $5,70 \pm 0,27$ & $5,80 \pm 0,27$ \\
ERMS, g MS/hora & $1.058,5 \pm 15,12 \mathrm{~A}$ & $1.006,2 \pm 15,12 \mathrm{~B}$ & $871,9 \pm 15,12 \mathrm{C}$ \\
ERFDN, g FDN/hora & $715,4 \pm 10,12 \mathrm{~A}$ & $660,0 \pm 10,12 \mathrm{~B}$ & $617,5 \pm 10,12 \mathrm{C}$ \\
\hline
\end{tabular}

ERMS - eficiência de ruminação da matéria seca; ERFDN - eficiência de ruminação da fibra em detergente neutro.

Letras maiúsculas distintas, na linha, diferem $(P<0,01)$ pelo teste t.

O tempo de ingestão de água (TIA) não foi influenciado $(\mathrm{P}>0,05)$ pelo tipo de volumoso utilizado na dieta. Esse comportamento era esperado, em virtude dos consumos de MS semelhantes entre as dietas (Tabela 3) e também porque os animais permaneceram dentro da zona de conforto térmico (Figura 2). Há evidências de que o consumo de água pelos animais ocorre principalmente nas primeiras horas da manhã e ao final da tarde (Hedlund \& Rolls, 1977). A maior influência no consumo de água, segundo o NRC (2001), é do tipo e da concentração de matéria seca no alimento, da temperatura ambiente e do nível de produção do animal.

Os tempos destinados ao ócio deitado e em pé foram influenciados pela substituição da silagem de milho pela de girassol. Animais que receberam apenas silagem de milho no volumoso permaneceram mais $(\mathrm{P}<0,05)$ tempo em ócio deitado em comparação aos alimentados com silagem de girassol; os valores foram de 7,91; 6,62 e 6,08 h/dia para as dietas 0;33 e 66\% de silagem de girassol, respectivamente. Para o tempo em ócio em pé, o comportamento foi semelhante entre os animais que receberam silagem de girassol, no entanto, permaneceram mais tempo em pé $(\mathrm{P}<0,05)$ em relação aos novilhos alimentados somente com silagem de milho. Resultados semelhantes foram obtidos por Polli et al. (1995), que, estudando o comportamento de bovinos e bubalinos em confinamento, verificaram que os animais alimentados com silagem de milho permaneceram mais $(\mathrm{P}<0,05)$ tempo em ócio deitado em relação aos alimentados com cana-de-açúcar (368 vs 320 min) e menos ( $\mathrm{P}<0,05)$ TOE ( 254 vs 286 min, respectivamente) quando alimentados com silagem de milho e canade-açúcar. O tempo de ócio total não diferiu entre as dietas e a média foi de 10,2 h/dia. Salla etal. (2003) verificaram que vacas Jersey apresentaram tempos de ócio de 9,86; 10,38; 9,93 e 10,05 h/dia, respectivamente, para as dietas controle, sebo, gordura protegida e grão de soja, enquanto Mendonça et al. (2004), comparando silagem de milho com cana-de-açúcar na alimentação de bovinos, verificaram que o tempo de ócio total foi menor $(\mathrm{P}<0,05)$ nos animais que consumiram a silagem de milho. Esses autores também estudaram a proporção de cana-de-açúcar na dieta com inclusão de ureia e não observaram diferença no tempo de ócio.

Os tempos destinados a ruminação em pé e total foram influenciados pela inclusão de silagem de girassol no volumoso. Os animais alimentados com maior proporção de silagem de girassol no volumoso permaneceram mais $(\mathrm{P}<0,05)$ tempo em ruminação em pé em relação aos que receberam apenas silagem de milho e o nível intermediário de silagem de girassol na dieta, que não diferiram entre si. Mesmo comportamento ocorreu em relação ao tempo de ruminação total, que elevou $(\mathrm{P}<0,05)$ conforme o aumento do nível de silagem de girassol na dieta. Os valores foram de 8,$61 ; 8,76$ e $9,45 \mathrm{~h} /$ dia, respectivamente, para os níveis 0 ; 33 e $66 \%$ de silagem de girassol. Neste estudo, o tempo de 
ruminação total apresentou baixa correlação com teor FDN da dieta $(r=0,3382 ; \mathrm{P}=0,0037)$, contrariando relatos de Welch \& Hooper (1988) que observaram correlação de 0,96 entre o tempo de ruminação total e o consumo de FDN.

O tempo de ruminação total observado foi próximo aos obtidos em vários estudos (Wilson \& Flynn, 1979; Metz, 1985; Camargo, 1988), os quais relataram que o tempo destinado à ruminação é de aproximadamente oito horas por dia em animais confinados.

Estudando o comportamento ingestivo de vacas Jersey alimentadas com diferentes fontes de gordura na dieta, Salla et al. (2003) não observaram diferença significativa entre as fontes de gordura para tempos de ruminação. Segundo esses autores, isso ocorreu pelo fato de que os níveis de EE das dietas não tiveram efeito negativo sobre a digestibilidade do volumoso nem sobre o consumo voluntário, e também porque as fontes de gorduras adicionadas eram palatáveis. Polli et al. (1995), analisando o comportamento ingestivo de bovinos e bubalinos em confinamento, alimentados com silagem de milho ou canade-açúcar, também não encontraram diferenças entre as fontes de volumoso nem entre os tempos despendidos com a ruminação, cujos valores médios de 8,5 e $8,2 \mathrm{~h}$ /dia para silagem de milho e cana-de-açúcar, respectivamente.

A coleta das informações relativas ao comportamento ingestivo dos animais possibilitou observar os picos de maior ocorrência da atividade de ingestão de alimento durante o dia e a noite. Em todos os tratamentos estudados, os horários de maior presença dos animais no comedouro coincidiram com horários próximos ao de fornecimento das dietas ( $8 \mathrm{~h} 30$ e às $14 \mathrm{~h}$ ) e ao entardecer.

Esses resultados corroboram as afirmações de Dulphy \& Faverdin (1987) de que o padrão de procura de alimento por animais em confinamento é bem característico, com dois momentos principais (ínício da manhã e final da tarde) e que o número e a duração das refeições são mais variáveis que os períodos de ruminação. Entretanto, as atividades ingestivas são ritmadas pela distribuição da ração e a quantidade fornecida influencia os picos de ocorrência da atividade ingestiva (Chase et al., 1976; Jaster \& Murphy, 1983).

Todos os animais reduziram o consumo de alimento próximo das $11 \mathrm{~h}$ (Figura 1) e por volta das $12 \mathrm{~h}$, os animais alimentados com 0 e $66 \%$ de silagem de girassol continuaram com redução desse consumo, enquanto os alimentados com 33\% de silagem de girassol aumentaram. Segundo Fischer et al. (1998), quando o alimento é distribuído duas vezes ao dia, as refeições que se seguem à distribuição do alimento são as mais importantes e duram cada uma de 1 a 3 horas.

A presença dos animais no comedouro no período noturno (19 as $6 \mathrm{~h}$ ) foi mais dispersa e menos concentrada que no período diurno. Esse resultado está de acordo com a literatura, pois o tempo gasto com a ingestão de alimento é intercalado com um ou mais períodos de ruminação ou de descanso (Jaster \& Murphy, 1983; Deswysen et al., 1993) e o tempo gasto durante a ruminação é mais elevado à noite (Polli et al., 1996).

A eficiência de ruminação de matéria seca, expressa em gramas de MS/hora, diferiu $(\mathrm{P}<0,01)$ com os níveis de silagem de girassol na dieta. Os animais alimentados apenas com silagem de milho foram 5,2 e $21,4 \%$ mais eficientes que os novilhos que receberam 33 e $66 \%$ de silagem de girassol na dieta, respectivamente. Essa melhor eficiência para a dieta que continha apenas de silagem de milho no volumoso ocorreu está relacionada ao menor tempo de ruminação total (Tabela 2) e também ao maior consumo numérico de MS, visto que a eficiência de ruminação da MS depende do nível de ingestão do alimento. Mendonça et al. (2004), estudando o comportamento de vacas leiteiras alimentadas

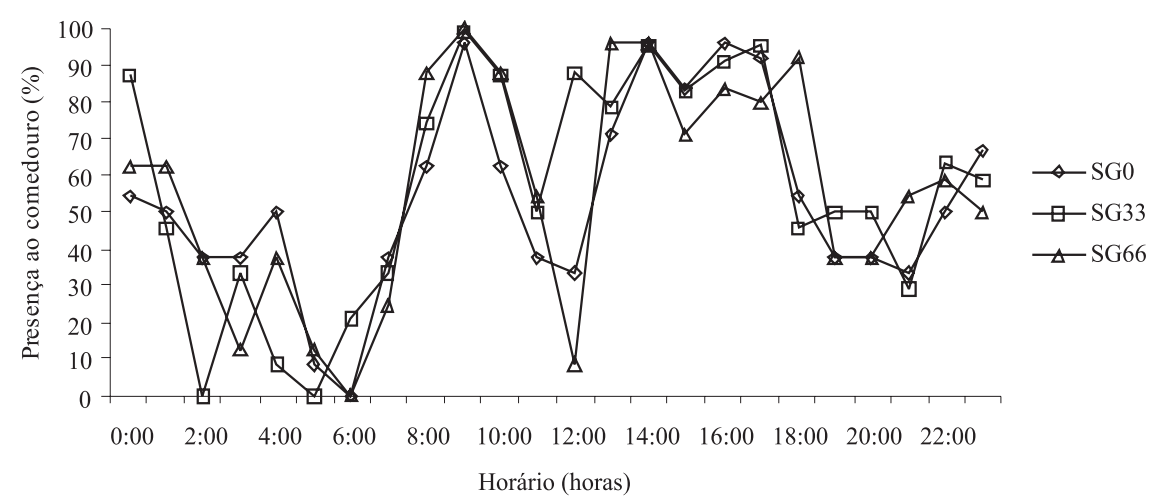

Figura 1 - Presença dos animais no comedouro (\%). 
com dietas à base de silagem de milho e cana-de-açúcar, não observaram diferença significativa para ERMS entre as fontes de volumosos.

Os resultados para a eficiência de ruminação da fibra em detergente neutro também foram significativos pela substituição da silagem de milho pela silagem de girassol no volumoso. A eficiência de ruminação da FDN foi maior $(\mathrm{P}<0,01)$ para a dieta à base de silagem de milho em relação àquelas que continham silagem de girassol, provavelmente em virtude da diferença na degradação ruminal da FDN entre as fontes de volumoso. Medonça et al. (2004) observaram diferença significativa para eficiência de ruminação da FDN entre as fontes de volumoso estudadas e que a eficiência de ruminação da FDN foi maior para a dieta à base de silagem de milho e não diferiu entre as dietas com cana-de-açúcar. Segundo Beauchemin \& Buchanan-Smith (1989), os tempos de ingestão e de ruminação variam de acordo com o conteúdo de fibra dietética. Quando os tempos de ruminação e mastigação são limitados, ocorre redução da produção de saliva, ocasionando diminuição do $\mathrm{pH}$ ruminal e da digestibilidade da fibra.

O número de mastigações merícicas/bolo e o tempo de mastigação total não foram influenciados $(\mathrm{P}>0,05)$ pelos níveis de silagem de girassol na dieta. Avaliando as silagens de milho ou cana-de-açúcar Polli et al. (1996) não encontraram diferença no número de mastigações merícicas/bolo, cujos valores foram de 55 e 54 (no/bolo) para as dietas contendo cana-de-açúcar e silagem de milho, respectivamente. Mendonça et al. (2004), avaliando o comportamento de vacas leiteiras alimentadas com cana-de-açúcar ou silagem de milho, observaram maior $(\mathrm{P}<0,05)$ tempo de mastigação total para os animais que receberam silagem de milho $(13,42 \mathrm{~h} /$ dia $)$ em relação aos animais alimentados com cana-de-açúcar+ureia (12,09 h/dia).

Os animais alimentados com $33 \%$ de silagem de girassol no volumoso destinaram mais $(\mathrm{P}<0,05)$ tempo de mastigação por bolo ruminal (TMB) em relação àqueles que receberam somente silagem de milho e os valores não diferiram do maior nível de inclusão de silagem de girassol.
Os valores obtidos neste trabalho são semelhantes aos encontrados por Polli et al. (1996) e Mendonça et al. (2004).

Houve efeito significativo $(\mathrm{P}<0,05)$ das dietas no número de bolos ruminados/dia, de modo que os animais alimentados apenas com silagem de milho e com maior nível de silagem de girassol no volumoso ruminaram, respectivamente, 9,7 e 15,5\% mais bolos ruminados/dia em relação aos bovinos tratados com nível intermediário de silagem de girassol na dieta. Polli et al. (1996), trabalhando com bovinos e bubalinos alimentados com cana-de-açúcar ou silagem de milho, não encontraram diferenças quanto ao número de bolos ruminados/dia: os animais que receberam cana-de-açúcar e silagem de milho ruminaram em média 521 e 575 bolos/dia, respectivamente. Deswysen et al. (1987), trabalhando com novilhas alimentadas com silagem de milho, constataram que os animais que consumiram mais alimentos apresentaram menor tempo de ruminação por bolo. Entretanto, neste estudo, não houve diferença significativa para o consumo de MS entre as dietas (Tabela 3 ).

O número de mastigações merícicas por dia foi maior $(\mathrm{P}<0,01)$ entre os bovinos que receberam maior nível de silagem de girassol em substituição à silagem de milho na dieta (Tabela 4). Essa diferença foi ocasionada pelo maior número de bolos mastigados pelos animais. Avaliando dois níveis de fibra na dieta de novilhas, Pereira et al. (2007) relataram que o aumento do nível de FDN da dieta de 30 para $60 \%$ aumentou o número de bolos ruminados/ dia de 28.446 para 35.105, enquanto Polli et al. (1996) encontraram valores médios de 28.710 e 30.988 mastigadas por dia para dietas com cana-de-açúcar e silagem de milho, respectivamente.

Não houve efeito das dietas no tempo de mastigação total, cujo valor médio foi de 13,6 h/dia. Allen (1997), em revisão da literatura, relatou os resultados de 132 tratamentos, média de 32 experimentos para o tempo de mastigação total e mencionaram o valor médio de $11,13 \mathrm{~h} / \mathrm{dia}$. Os resultados deste trabalho são superiores aos obtidos por esse autor.

O número de refeições diárias (Tabela 5) não foi influenciado $(\mathrm{P}>0,05)$ pela inclusão da silagem de girassol

Tabela 4 - Número de bolos ruminados por dia, número de mastigações merícicas por bolo e diárias, tempo de mastigação por bolo ruminal e mastigação total, de novilhos alimentados com diferentes níveis de silagem de girassol na dieta

\begin{tabular}{lccc}
\hline Item & \multicolumn{3}{c}{ Dieta* } \\
\cline { 2 - 4 } & $100 \mathrm{SM}$ & $33 \mathrm{SG}$ & $66 \mathrm{SG}$ \\
\hline Bolos (no/dia) & $587 \pm 13,61 \mathrm{a}$ & $535 \pm 13,61 \mathrm{~b}$ & $618 \pm 13,61 \mathrm{a}$ \\
Mastigações merícicas (no/bolo) & $59 \pm 1,78$ & $61 \pm 1,78$ & $64 \pm 1,78$ \\
Mastigações por bolo (seg) & $53 \pm 1,41 \mathrm{~b}$ & $59 \pm 1,41 \mathrm{a}$ & $56 \pm 1,41 \mathrm{ab}$ \\
Mastigações diárias (no/dia) & $34.256 \pm 614,24 \mathrm{~B}$ & $32.555 \pm 614,24 \mathrm{~B}$ & $38.742 \pm 614,24 \mathrm{~A}$ \\
Mastigação total (horas/dia) & $13,2 \pm 0,19$ & $13,7 \pm 0,19$ & $13,8 \pm 0,19$ \\
\hline
\end{tabular}

Letras maiúsculas distintas, na linha, diferem $(\mathrm{P}<0,01)$ pelo teste $\mathrm{t}$.

Letras minúsculas distintas, na linha, diferem $(\mathrm{P}<0,05)$ pelo teste $\mathrm{t}$ 
na dieta e o valor médio foi de 10,48 refeições ao dia, enquanto, para o tempo despendido por refeição, houve efeito $(\mathrm{P}<0,01)$ da substituição da silagem de milho pela silagem de girassol. O maior tempo despendido por refeição foi obtido para as dietas contendo apenas somente silagem de milho como fonte de volumoso (32,58 min) e o menor, com aumento da inclusão de silagem de girassol no volumoso, sendo os valores de 28,33 e 23,46 min, respectivamente, para 33 e $66 \%$ de silagem de girassol. Esta diferença está relacionada à maior $(\mathrm{P}<0,05)$ eficiência de ruminação da MS e eficiência de ruminação da FDN para a dieta com apenas silagem de milho como fonte de volumoso (Tabela 3). A maior taxa de ingestão da MS está relacionada ao aumento na taxa de passagem da fibra nos compartimentos ruminais e ao menor tempo de retenção da FDN (Dado\& Allen, 1995). Johnson \& Combs (1991), alimentando vacas holandesas em lactação com silagem de alfafa e silagem de milho suplementadas com farelo de soja, registraram o tempo despendido por refeição de 14,7 minutos e 18 refeições diárias. Burger et al. (2000) observaram que o NRF não foi influenciado pelos níveis de concentrado e encontraram valor médio de 14,8 horas, enquanto, para o tempo despendido por refeição, ocorreu efeito linear decrescente $(\mathrm{P}<0,01)$ dos níveis de concentrado.

A temperatura mínima registrada foi de $10,3^{\circ} \mathrm{C}$ e máxima de $22,3^{\circ} \mathrm{C}$ (Figura 2). Os resultados estão dentro dos limites

Tabela 5 - Valores médios para o número de refeições diárias (NRF) e tempo despendido por refeição (TRF), de novilhos alimentados com diferentes níveis de silagem de girassol na dieta

\begin{tabular}{lccc}
\hline Item & \multicolumn{3}{c}{ Nível de silagem de girassol $(\% \mathrm{MS})$} \\
\cline { 2 - 4 } & 0 & 33 & 66 \\
\hline Refeições, no/dia & $9,71 \pm 0,39$ & $10,87 \pm 0,39$ & $10,87 \pm 0,39$ \\
Tempo despendido & $32,58 \pm 1,34 \mathrm{~A}$ & $28,33 \pm 1,34 \mathrm{~B}$ & $23,46 \pm 1,34 \mathrm{C}$ \\
por refeição, min & & & \\
\hline
\end{tabular}

Letras maiúsculas distintas, na linha, diferem $(\mathrm{P}<0,01)$ pelo teste $\mathrm{t}$.

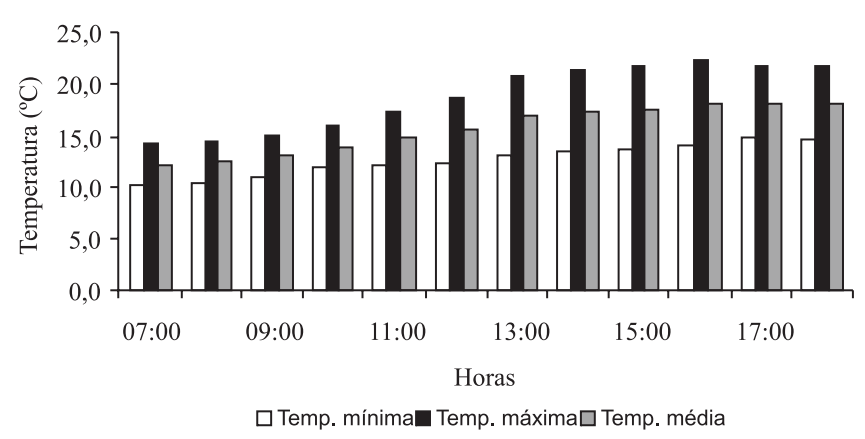

Figura 2 - Temperatura mínima, máxima e média registrados no período diurno (7 às $18 \mathrm{~h}$ ). de conforto térmico, entre 4,44 a $23,88^{\circ} \mathrm{C}$ e indicam que os animais não estavam sob estresse térmico (Fraser, 1995).

\section{Conclusões}

Novilhos alimentados com silagem de girassol ruminam por mais tempo. A eficiência de ruminação, quando expressa em $\mathrm{g}$ FDN/horas, é maior para dietas à base de silagem de milho que para as dietas com silagem de girassol. A substituição da silagem de milho por girassol na dieta não influencia o número de refeições diárias, mas diminui o tempo despendido por refeição.

\section{Agradecimentos}

À empresa Heliantus do Brasil pela doação das sementes dos híbridos de girassol Helio $251^{\circledR}$ e Helio $360^{\circledR}$. À empresa Biomatrix pela doação das sementes de milho BR3150 ${ }^{\circledR}$. À empresa Corn Products pela facilitação na aquisição do farelo de glúten de milho. À Elanco pela doação do Ionóforo (Rumensin ${ }^{\circledR}$ ).

\section{Referências}

ALBRIGHT, J.L. Nutrition, feding and calves. In: Feeding behavior of dairy cattle. Journal of Animal Science, v.76, p.485-498, 1993.

ALLEN, M.S. Relationship between fermentation acid production in the rumen and the requirement for physically effective fiber. Journal of Dairy Science, v.80, n.7, p.1447-1462. 1997.

ASSOCIATION OF OFFICIAL ANALYTICAL CHEMISTRY AOAC. Official methods of analysis. 16.ed. Washington, D.C.: 1995. 2000p.

BENSON, J.A.; REYNOLDS, C.K.; HUMPHRIES, D.J. et al. Effects of abomasal infusion of long-chain fatty acids on intake, feeding behavior and milk production in dairy cows. Journal of Dairy Science, v.84, p.1182-1191, 2001.

BEAUCHEMIN, K.A.; BUCHANAN-SMITH, J.G. Effects of dietary neutral detergent fiber concentration and supplementary long hay on chewing activities and milk production of dairy cows. Journal of Dairy Science, v.2, n.9, p.2288-2300, 1989.

BURGER, P.J.; PEREIRA, J.C; QUEIROZ, A.C. et al. Comportamento ingestivo em bezerros holandeses alimentados com dietas contendo diferentes níveis de concentrado. Revista Brasileira de Zootecnia, v.29, n.1, p.236-242, 2000.

CAMARGO, A.C. Comportamento de vacas da raça holandesa em um confinamento do tipo free stall, no Brasil central. 1988. 146f. Dissertação (Mestrado em Zootecnia) - Escola Superior de Agricultura "Luiz de Queiroz", Piracicaba.

CHASE, L.E.; WANGSNESS, P.J.; BAUMGARDT, B.R. Feeding behavior of steers fed a complete mixed ration. Journal of Dairy Science, v.59, n.11, p.1923-1928, 1976.

DADO, R.G.; ALLEN, M.S. Intake limitations, feeding behavior, and rumen function of cows challenged with rumen fill from dietary fiber or inert bulk. Journal of Dairy Science, v.78, n.1, p.118-133, 1995.

DESWYSEN, A.G.; ELLIS, W.C.; POND, K.R. Interrelationships among voluntary intake, eating and ruminating behavior and ruminal motility of heifers fed corn silage. Journal of Animal Science, v.64, n.3, p.835-841, 1987. 
DESWYSEN, A.G.; DUTILLEUL, P.A.; GODFRIN, J.P. et al. Nycterohemeral eating and ruminating patterns in heifers fed grass or corn silage: analysis by finite Fourier transform. Journal of Animal Science, v.71, n.10, p.2739-2747, 1993.

DULPHY, J.P.; REMONND, B.; THERIEZ, M. Ingestive behavior and related activities in ruminants. In: Digestive physiology and metabolism in ruminants. Connecticut, A.V.I., Publ. Co., Inc. Wesport, 1980. p.103-122.

DULPHY, J.P.; FAVERDIN, P. L'ingestion alimentaire chez les ruminats: modalités et phénomènes associés. Reproduction, Nutrition and Dévelopment, v.27, n.2, p.129-155, 1987.

FERREIRA, J.J. Desempenho e comportamento ingestivo de novilhos e vacas sob frequências de alimentação em confinamento. 2006. 80f. Dissertação (Mestrado em Zootecnia) - Universidade Federal de Santa Maria, Santa Maria.

FISCHER, V.; DESWYSEN, A.G.; AMOUCHE, E.H. et al. Efeitos da pressão de pastejo sobre o padrão nectemeral do comportamento ingestivo de ovinos em pastagem. Revista Brasileira de Zootecnia, v.27, n.1, p.164-170, 1998.

FISCHER, V.; FERREIRA, E.X.; MORENO, C.B. et al. Comportamento ingestivo de vacas Jersey na fase inicial de lactação alimentadas com dietas contendo diferentes fontes de gordura - ano II. In: REUNIÃO DA ASSOCIAÇÃO LATINO AMERICANA DE PRODUÇÃO ANIMAL, 17., 2001, Havana. Anais... Havana: Associação Latino Americana de Produção Animal, 2001. (CD-ROM).

FORBES, J.M. Voluntary food intake and diet selection in farm animals. Wallingford: CAB, 1995. 532p.

FRASER, A.F. Farm animal behaviour. Baltimore: Williams \& Wilkins Company, 1995. 196p.

HAFEZ, E.S.E.; LINDSAY, D.R. Behavioural responses in farms animal and their relevance to research techiniques. Animal Breed Abstract, v.33, n.1, p.1-16, 1965.

HEDLUND, L.; ROLLS, J. Behavior of lactating dairy cows during total confinament. Journal of Dairy Science, v.60, n.11, p.1807-1812, 1977.

JASTER, E.H.; MURPHY, M.R. Effects of varying particle size of forage on digestion and chewing behavior of dairy heifers. Journal of Dairy Science, v.66, n.6, p.802-810, 1983.

JOHNSON, T.R.; COMBS, D.K. Effects of prepartum diet, inert rumen bulk, and dietary polythylene glicol on dry matter intake of lactating dairy cows. Journal of Dairy Science, v.74, n.3, p.933-944, 1991

KOMAREK, A.R. A fiber bag procedure for improved efficiency of fiber analyses. Journal of Dairy Science, v.76, p.250, 1993. (supll. 1).

KOZLOSKI, G.V. Bioquímica dos ruminantes. Santa Maria: Imprensa Universitária - UFSM, 2002. 139p.

LICITRA, G.; HERNANDEZ, T.M.; VAN SOEST, P.J. Standartization of procedures for nitrogen fractionation of ruminant feeds. Animal Feed Science Technology, v.57, p.347-358, 1996 .
MENDONÇA, S.S.; CAMPOS, J.M.S.; VALADARES FILHO, S.C et al. Comportamento ingestivo de vacas leiteiras alimentadas com dietas à base de cana-de-açúcar ou silagem de milho. Revista Brasileira de Zootecnia, v.33, n.3, p.723-728, 2004.

METZ, J.H.M. The reaction of cows to short-term deprivation of lying. Applied Animal Behaviour Science, v.13, p.301$307,1985$.

NATIONAL RESEARCH COUNCIL - NRC. Nutrient requirements of beef cattle. 7.ed. Washington, D.C.: 1996. $232 \mathrm{p}$.

NATIONAL REQUIREMENT COUNCIL - NRC. Nutrient requirements of beef cattle. 7.ed. Washington, D.C. National Academy Press, 2001. 242p.

PEREIRA, J.C.; DANIEL, N.F.V.C.; CECON, P.R. et al. Comportamento ingestivo e taxa de passagem de partículas em novilhas leiteiras de diferentes grupos genéticos submetidas a dietas com diferentes níveis de fibra. Revista Brasileira de Zootecnia, v.36, n.6, p.2134-2142, 2007. (supl.).

POlli, V. A.; RESTlE, J.; SENNA, D.B. Comportamento de bovinos e bubalinos em regime de confinamento. I. Atividades. Ciência Rural, v.25, n.1, p.127-131, 1995.

POLLI, V.A.; RESTLE, J.; SENNA, D.B. et al. Aspectos relativos à ruminação de bovinos e bubalinos em regime de confinamento. Revista Brasileira de Zootecnia, v.25, n.5, p.987-993, 1996.

ROBERTSON, J.B.; VAN SOEST, P.J. The detergent system of analysis. In: JAMES, W.P.T.; THEANDER, O. (Eds.) The analysis of dietary fibre in food. New York: Marcel Dekker, 1981. p.123-158

SALLA, L.E.; FISCHER, V.; FERREIRA, E.X. et al. Comportamento ingestivo de vacas Jersey alimentadas com dietas contendo diferentes fontes de gordura nos primeiros 100 dias de lactação. Revista Brasileira de Zootecnia, v.32, n.3, p.683-689, 2003.

STATISTICAL ANALYSIS SYSTEM - SAS. SAS language reference. Version 6. Cary: SAS Institute, 2001. 1042p.

SCHAUFF, D.J.; ELLIOTT, J.P.; CLARK, J.H. et al. Effect of feeding lactating dairy cows diets containing extrude soybeans and calcium salts of long-chain fatty acids. Journal of Dairy Science, v.75, p.3003-3019, 1992

WEISS, W.P.; CONRAD, H.R.; ST. PIERRE, N.R. A theoreticallybased model for predicting total digestible nutrient values of forages and concentrates. Animal Feed Science and Technology, v.39, p.95-110, 1992.

WELCH, J.G., HOOPER, A.P. Ingestion of feed and water. In: CHURCH, D.C. (Ed.) The ruminant animal: digestive physiology and nutrition. Englewood Cliffs: Reston, 1988 p.108-116.

WILSON, R.K.; FLYNN, A.V. Feeding behavior of cattle when offered grass silage in troughs during winter and summer. Applied Animal Ethology, v.5, n.1, p.35-41, 1979. 